\title{
Research and Design of College Chinese Teaching based on the Diversified Teaching Method
}

\author{
Xuliqin $^{1}$, JiangXiaoli ${ }^{2}$ \\ 1. Nanchang Institute of Science \&Technology, Nanchang 330108, China; \\ 2.Shangrao Vocational \& Technical College, Shaorao 334109, China
}

\begin{abstract}
Keywords: Diversified teaching; College Chinese; Teaching design; Learning motivation; Reinforcement.
\end{abstract}

\begin{abstract}
The teaching effect of college Chinese teaching is not satisfactory. In the course of teaching, teachers' teaching method is single, and students' learning interest is low and pays no attention. They can't not only grasp the basic theoretical knowledge and skills, and even the understanding of the course is wrong, so it is necessary to reform the teaching of college Chinese course. Under this background, this paper presents a diversified teaching method based on multimedia and network technology, and constructs a system framework of diversified teaching platform, which improves the teaching level of college Chinese. Based on the statistical analysis of the final score and normal operating results, the results showed that the diversified teaching method can not only improve the students' average academic performance, but also enhance the students' learning interest and motivation, and promote their cooperation and innovation ability, so as to improve the design level of college Chinese teaching.
\end{abstract}

\section{Introduction}

In recent years, with the new reform of teaching, the university and even primary and middle school teachers are trying to explore teaching design and teaching reform, which is the focus on the "task driven", " learning based on problem " and other ways to pay attention to students "learning" activities[1-3]. But this does not mean that the traditional teaching method has nothing to recommend. In the teaching process, it is necessary to select the appropriate teaching method for the characteristics of students and the specific teaching content. It needs to use different teaching methods for different knowledge points in a unit or even a class, which needs to adopt a diversified teaching method. This research is based on the multimedia network technology, based on the diversified teaching method as the starting point, according to the shortcoming of current Chinese language teaching, the experimental study of the Chinese language teaching is studied to improve the level of university Chinese teaching.

\section{The Diversified Teaching Methods for College Chinese}

Diversified university Chinese teaching method uses the different types of knowledge to choose different teaching methods, for the basic theory part, it can be combined with the content of the textbook to design the teaching in the way of questing; knowledge and skills can be combined with the teaching experience and the existing multimedia network resources to improve the ability of independent learning and innovation [4,5]. For teaching design part, it can use case teaching and task driven way to complete. Therefore, in the theoretical part of the teaching, students can not only be confined to the boring and abstract content, but can be lively and vivid to question and solve problems, so they can further understand the connotation of theoretical knowledge [6]. In order to improve students' ability to master knowledge, teachers can set related tasks, which is driven by autonomous learning to complete and they can make full use of existing network and multimedia resources, and use these resources and teachers to implement interactive and improve teaching efficiency. 


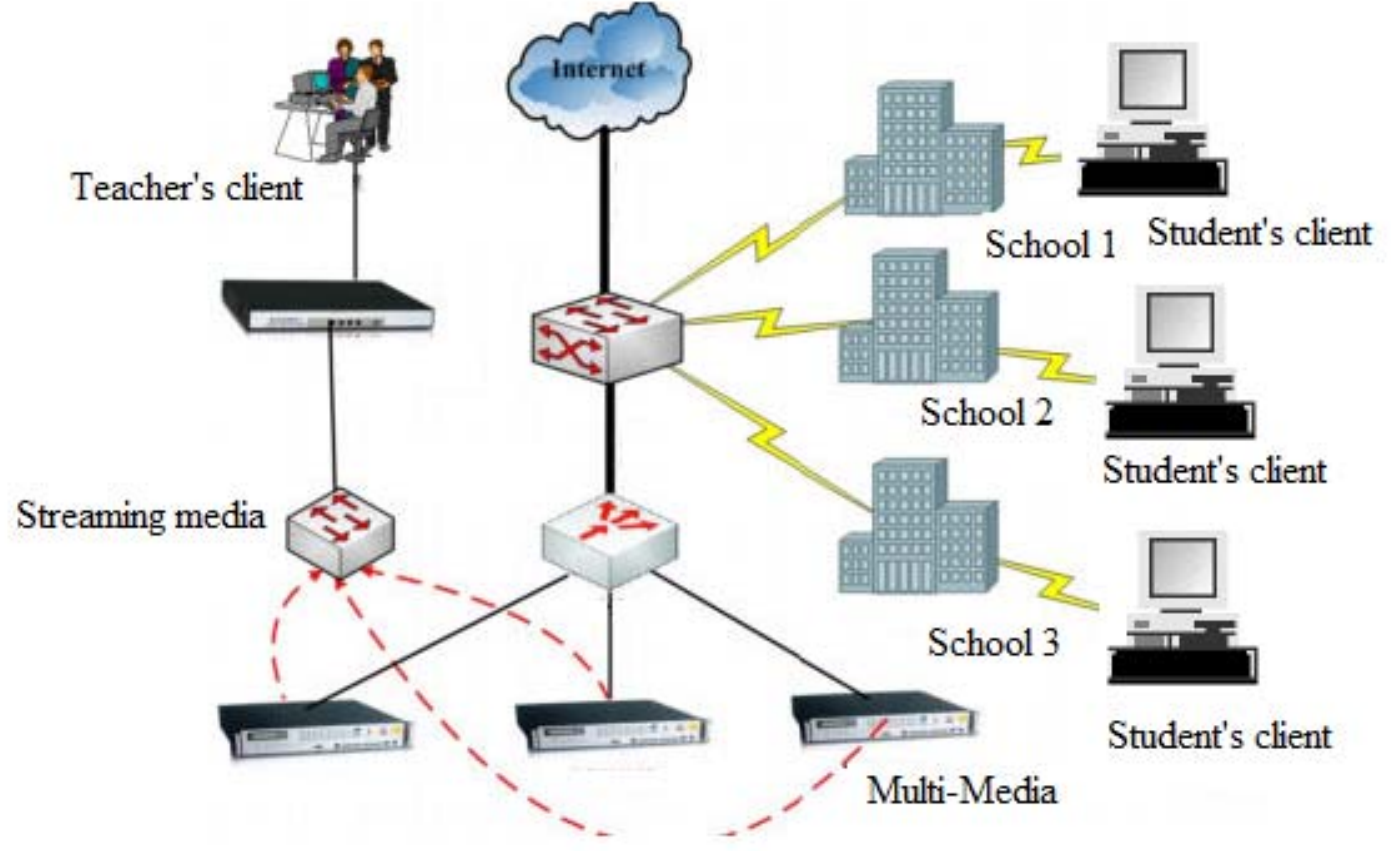

Fig.1 Multi Chinese teaching multimedia internet platform

Figure 1 shows the framework of multi Chinese teaching multimedia platform. The main design idea is to take the teacher as the main teaching mode and the students as the main teaching mode. The teacher can release the content of teaching through the teacher's client, and the student uses the student's client to accept the new content. Using multimedia technology, teachers can design the curriculum content lively and rich, students can also communicate with the teachers through the implementation of interactive module. In the active role of the multimedia internet platform, students not only learn the basic theory of language, but also improve the ability of information technology and professional disciplines.

\section{Multimedia Network Optimization of Diversified Teaching}

For the college diversified teaching, this research mainly uses the multimedia and the network method to realize, because the current university has a very high usage rate of the network, and this method is easy for students to accept [7-9]. In order to realize the smooth of the network and guarantee the real-time transmission of multimedia content and real-time interaction between students and teachers, it needs to optimize the network. Assumed that the flow media function of multimedia content in the network transmission is $y=f(x)$, using a specific numerical calculation method, and the use of interpolation algorithm can accelerate the convergence of the calculation and improve the network transmission speed. The interpolation calculation process is as follows:

$$
\begin{aligned}
p_{2}(x)= & f\left(x_{i}\right)+f\left[x_{i}, x_{i-1}\right]\left(x-x_{i}\right) \\
& +f\left[x_{i}, x_{i-1}, x_{i-2}\right]\left(x-x_{i}\right)\left(x-x_{i-1}\right)
\end{aligned} .
$$

The zero expression of the interpolation function is:

$$
x_{i+1}=x_{i}-\frac{2 f\left(x_{i}\right)}{z \pm \sqrt{\omega^{2}-4 f\left(x_{i}\right) f\left[x_{i}, x_{i-1}, x_{i-2}\right]}} .
$$

The expression of $\omega$ is:

$Z=f\left[x_{i}, x_{i-1}\right]+f\left[x_{i}, x_{i-1}, x_{i-2}\right]\left(x_{i}-x_{i-1}\right)$.

Based on the above ideas, the flow media function $y=f(x)$ is done Newton interpolation, so it can get: 


$$
\begin{aligned}
& x_{i+1}=x_{i}-\frac{f\left(x_{i}\right)}{f^{\prime}\left(x_{i}\right)} . \\
& f^{\prime}\left(x_{i}\right) \text { is } \frac{f\left(x_{i}\right)-f\left(x_{i-1}\right)}{x_{i}-x_{i-1}}, \text { so } y \text { is: } \\
& y=f\left(x_{i}\right)+\frac{f\left(x_{i}\right)-f\left(x_{0}\right)}{x_{i}-x_{0}}\left(x-x_{i}\right) .
\end{aligned}
$$

Through the above algorithms, we can guarantee the stability of multimedia information content transmission. The purpose of establishing a multimedia internet platform is to enrich the students' learning content and achieve the purpose of diversification teaching [10]. Another important reason is to realize the real-time interaction between teachers and students, and the interactive process flow is as shown in Figure 2.

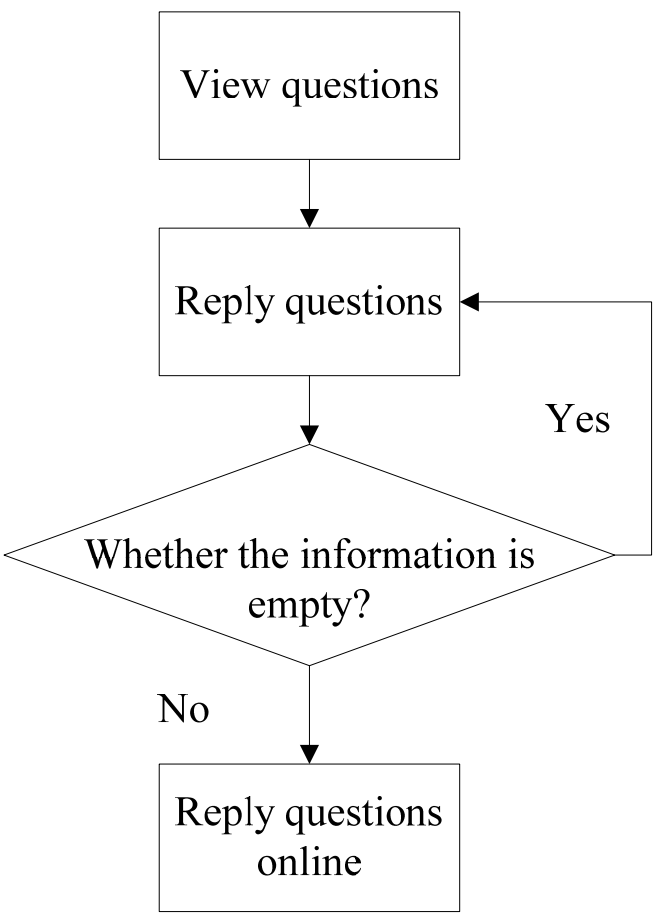

Fig. 2 Diversified teaching real time interactive process

Using the multimedia network platform, teachers can check the students' questions in the list of questions, and reply the students' questions and solve the problems of the students in their learning. In the system design, the conditional statements to determine whether the reply message is empty, if it is empty, it will reply the error message box; if the content is not empty, then reply content to write data, the database updates the data. For the deletion of content of the deletion, it can use ID value to check, and then execute the SQL delete statement; finally can complete the deletion of the content.

\section{Experimental Analysis of Diversification College Chinese Teaching}

This experiment chooses two kinds of classes, including two experimental classes, two contrast classes. The experimental class uses a diversified teaching method, while the contrast class still retains the traditional teaching mode, and the basic number of cases is shown in Table 1.

Table 1 The basic number of in experimental classes and contrast classes

\begin{tabular}{|c|c|c|c|}
\hline Class & Total number & Number of boys & Number of girls \\
\hline Experimental class 1 & 42 & 28 & 14 \\
\hline Experimental class 2 & 43 & 25 & 18 \\
\hline Contrast class 1 & 45 & 23 & 22 \\
\hline Contrast class 2 & 46 & 21 & 25 \\
\hline
\end{tabular}


Table 1 shows the basic number in experimental class and contrast class. The assessment method is the same as other public course assessment, and course score accounts for $40 \%$ of regular grades, final exam accounts for $60 \%$. The exam is in a closed volume way, and regular grades focus on the academic and practical. The experimental class teaching contents are as follows [11,12]:

(1) Characteristic analysis of learners: after a few weeks of the study for the experimental class and a collaborative group, they learn independent communication, but without guide, students are too lazy to think, accustomed to listening and watching, mainly to understand the teacher lectures, less independent thinking.

(2) Textbook analysis: the analysis of the teaching material should grasp the basic theory knowledge, and then use the multimedia network technology to analyze the content and improve the content of the lecture.

(3) Design intent: through playing the multimedia clips, let the students grasp the content of the course, and put forward the problem, through the task driven method to make the students take the initiative to think about the problem.

(4) Learning objectives: first, knowledge and skills, students can understand the basic content of the text and master basic grammar, vocabulary and writing methods, and then the process and methods, in the process of communication students can improve their learning interest, enhance the thinking and consciousness ability. Finally it can enhance the students' emotional attitude and values, so that students can correctly understand the textbook content, willing to use multimedia and network technology to enhance self-learning ability, through the way of group collaboration, improve the ability to communicate with others and division of labor.

(5) Teaching key and difficult points: the using of multimedia network modern diversified teaching system.

Through a semester of study, the experimental classes and contrast classes and the work of the case and study results are statistically obtained, as shown in Table 2.

Table 2. Job submission and academic performance statistics

\begin{tabular}{|c|c|c|c|c|c|c|}
\hline Project & \multicolumn{2}{|c|}{ First } & \multicolumn{2}{c|}{ Second } & \multicolumn{2}{c|}{ Third } \\
\hline Class & $\begin{array}{c}\text { Experimental } \\
\text { class }\end{array}$ & $\begin{array}{c}\text { Contrast } \\
\text { class }\end{array}$ & $\begin{array}{c}\text { Experimental } \\
\text { class }\end{array}$ & $\begin{array}{c}\text { Contrast } \\
\text { class }\end{array}$ & $\begin{array}{c}\text { Experimental } \\
\text { class }\end{array}$ & $\begin{array}{c}\text { Contrast } \\
\text { class }\end{array}$ \\
\hline $\begin{array}{c}\text { Total } \\
\text { number }\end{array}$ & 85 & 91 & 85 & 91 & 85 & 91 \\
\hline $\begin{array}{c}\text { Final } \\
\text { submission }\end{array}$ & 84 & 81 & 85 & 83 & 85 & 85 \\
\hline $\begin{array}{c}\text { The highest } \\
\text { score }\end{array}$ & 92 & 88 & 95 & 89 & 97 & 91 \\
\hline Mean score & 82 & 71 & 85 & 73 & 83 & 70 \\
\hline
\end{tabular}

Table 2 shows statistics of students' three homework and final score in one semester. From the table it can be seen, compared with the contrast class, the number of students who submit assignment in the experimental class is higher than that in the contrast group, which means that the diversified teaching method improves the students' learning interest and improves the enthusiasm of the work. By the final score, the average score and the highest score of the experimental class is higher than that in the contrast group, which means that the diversified teaching method can not only improve the students' learning interest, but also improve the students' learning ability, so it is an effective teaching method.

\section{Summary}

This study is combined with the actual situation of college Chinese teaching, according to the characteristics of students, it puts forward a new diversified teaching method, through multimedia and internet technology, this paper designs a diversified teaching platform system. In order to verify 
the effectiveness of the diversified teaching method, the teaching experiment is carried out and the experimental class and the contrast class are set up. Through the analysis of class assignments submitted and final results, the coursework submission rate and inspect grades in experimental class are better than the contrast class, which shows that the diversified teaching method can not only effectively improve the students learning enthusiasm and interest in learning, but also can effectively improve learning ability to achieve better teaching effect.

\section{References}

[1] G.F. Zhang. Talking about the model teaching of "working task driving method". Education and occupation, 2014, 4(3): 80-81.

[2] W. Yu. The task-based teaching is an effective way to achieve the goal of the new curriculum teaching. Technology Wenhui, 2013, 2(4): 126-127.

[3] J. Gao. The internal motivation of German enterprises to participate in vocational education. Foreign primary and middle school education, 2014, 3(8): 16-18.

[4] J. Zhou, Z.J. Zhao. The present situation and thinking about the construction of modern education technology in public class. China education technology equipment, 2014, 5(2): 22-23.

[5] X.F. Liu. The current situation of the construction of modern education technology public course. Journal of Guangzhou Open University, 2013, 2(4): 46-51.

[6] M. Liu Mei. The Enlightenment of the modern educational technology in Singapore. Chinese audio visual education, 2013, 4 (11): 102-103.

[7] C.Z. Liu, W.M. Zhang. Discussion of modern education technology teaching content. Modern education technology, 2014, 2(3): 54-56.

[8] F.Y. Li. The application and thinking of multimedia in English teaching. Chinese information technology education , 2013, 4 (8): 43-45.

[9] L.J. Song. The psychological characteristics of middle school students in English teaching. Education exploration, 2014, 5 (3): 55-56.

[10] Y. Yang. The advantages and disadvantages of multimedia teaching in English teaching. Journal of Jilin radio and TV University, 2013, 4(6): 146-147.

[11] X.Q. Wang. The theory and practice of higher mathematics teaching mode. Jilin education, 2013, 3 (11): 20- 21

[12] D.H. Mao. The research on the mathematics teaching in Higher Vocational Colleges. Journal of Chongqing Vocational and Technical College, 2013, 16 (4): 43- 44. 